\title{
Contemporary ordinary language philosophy
}

Article

Accepted Version

Hansen, N. (2014) Contemporary ordinary language philosophy. Philosophy compass, 9 (8). pp. 556-569. ISSN 1747-9991 doi: https://doi.org/10.1111/phc3.12152 Available at https://centaur.reading.ac.uk/37465/

It is advisable to refer to the publisher's version if you intend to cite from the work. See Guidance on citing.

To link to this article DOI: http://dx.doi.org/10.1111/phc3.12152

Publisher: Wiley

All outputs in CentAUR are protected by Intellectual Property Rights law, including copyright law. Copyright and IPR is retained by the creators or other copyright holders. Terms and conditions for use of this material are defined in the End User Agreement.

\section{www.reading.ac.uk/centaur}

\section{CentAUR}

Central Archive at the University of Reading

Reading's research outputs online 


\title{
Contemporary Ordinary Language Philosophy*
}

\author{
Nat Hansen \\ Forthcoming in Philosophy Compass
}

\begin{abstract}
There is a widespread assumption that ordinary language philosophy was killed off sometime in the 1960s or 70s by a combination of Gricean pragmatics and the rapid development of systematic semantic theory. ${ }^{1}$ Contrary to that widespread assumption, however, contemporary versions of ordinary language philosophy are alive and flourishing, but going by various aliases-in particular (some versions of) "contextualism" and (some versions of) "experimental philosophy". And a growing group of contemporary philosophers are explicitly embracing the methods as well as the title of ordinary language philosophy and arguing that it has been unfairly maligned and was never decisively refuted. In this overview, I will outline the main projects and arguments employed by contemporary ordinary language philosophers, and make the case that updated versions of the arguments made by ordinary language philosophers in the middle of the twentieth century are attracting renewed attention.
\end{abstract}

\section{Contemporary Ordinary Language Philosophy: Two Projects}

In this overview I will discuss two projects that constitute contemporary ordinary language philosophy: a constructive project and a critical project. Both are descendants of projects pursued by "classic" (mid 20th-century) ordinary language philosophers. The constructive project moves from observations about how certain words are used to facts about the meaning of those words, and then draws conclusions about the "realities" those words are used to

*Thanks to Zed Adams, Jonas Åkerman, Avner Baz, Alex Davies, Aidan Gray, Jumbly Grindrod, Martin Gustafsson, Eliot Michaelson, Chauncey Maher, an anonymous referee, and the editors Kathrin Glüer Pagin and Peter Pagin for very helpful comments.

${ }^{1}$ See Chapman (2005, p. 3), Forguson (2001, p. 325), Parker-Ryan (2012), Soames (2003), Stanley (2008), and Travis (1985). Even contemporary advocates of ordinary language philosophy recognize that it may appear obsolete (Laugier, 2013, p. 9) and that there is a widely held belief that it is "seriously discredited" (Baz, 2012b, p. 1). 
talk about. The constructive project is a continuation of J.L. Austin's (1956, p. 8) practice of using a "sharpened awareness of words" to "sharpen our perception of... the phenomena". The critical project involves arguing that philosophers produce "nonsense" or don't really understand what they are saying when they depart from or ignore the way language is ordinarily used. Classic inspirations for the critical project include Wittgenstein's (1969, $\S 10)$ remark that when one is sitting at a sick man's bedside, looking attentively into his face, neither the question "I know that a sick man is lying here?" nor the assertion "I don't know that there is a sick man lying here" makes sense and Austin's (1962, p. 15) argument that the word "directly" has been "stretched" by philosophers to the point that it has become "meaningless".

The constructive and critical projects in contemporary ordinary language philosophy are separable: one can engage in the constructive project without thinking that philosophers are prone to produce nonsense when they depart from ordinary language, and one can engage in the critical project and not draw any conclusions about extra-linguistic reality from the way people ordinarily speak (Baz's 2012b "essentially responsive" way of conducting ordinary language philosophy pursues this latter approach, for example).

There is a long tradition of criticizing versions of these two projects as they were developed by classic ordinary language philosophers. I will argue that some of the standard objections to classic ordinary language philosophy can be met, and that, while there remain reasonable objections to the contemporary versions of both of these projects, contemporary ordinary language philosophers pursue these projects in ways that are worthy of serious consideration.

\section{The constructive project}

The constructive project in contemporary ordinary language philosophy involves moving from observations about the ordinary use of philosophically significant expressions (e.g., 
"knows") to conclusions about non-linguistic aspects of the world (the nature of knowledge, e.g.). ${ }^{2}$

The constructive project has an initial semantic stage that is followed by a metaphysical stage. The semantic stage aims to establish conclusions about the meaning of an expression on the basis of facts about how the expression is ordinarily used. The metaphysical stage aims to establish conclusions about the nature of what the target expression refers to on the basis of the meaning of the expression.

\section{Semantic Stage}

1. An expression " $\mathrm{X}$ " is ordinarily used in way $\mathrm{Y}$.

2. The best explanation of the fact that " $\mathrm{X}$ " is ordinarily used in way Y requires the semantics ("linguistic meaning") of "X" to have feature(s) F.

\section{Metaphysical Stage}

3. Semantics constrains metaphysics: If the semantics of " $X$ " has feature(s) F, then the nature of what " $\mathrm{X}$ " refers to- $\mathrm{X}-$ will have feature(s) $\mathrm{G}$.

Each element of the constructive project has been intensely disputed from the heyday of classic ordinary language philosophy up to the present day.

\subsection{Drawing Conclusions about Meaning from Observations about Ordinary Use}

A standard worry about classic ordinary language philosophy is that it fails to recognize that conclusions about the meaning of an expression do not follow directly from observations about the ordinary use of that expression. This worry dates back at least to Grice (1961),

\footnotetext{
${ }^{2}$ For discussion of the linguistic components of epistemological contextualism and how it is supposed to bear on metaphysical issues, see Ludlow (2005). Stanley's (2011a,b) and Stanley and Williamson's (2001) linguistic arguments for intellectualism about knowledge how have also been compared to ordinary language philosophy (though their arguments rely more on the details of one type of syntactic theory than on how language is ordinarily used). For discussion, see Abbott (2013), Chalmers (2012), and Noë (2005, p. 286).
} 
who defends sense-data-based theories of perception against the attacks of ordinary language philosophers by criticizing them for failing to recognize that conclusions about the meaning of "looks" and related expressions do not follow directly from observations about the ordinary use of those expressions. ${ }^{3}$ I'll discuss one version of this worry before going on to describe an example of how contemporary ordinary language philosophers respond to it.

Consider the following skeptical argument schema:

1. You can't rule out the possibility that you're dreaming that $P$.

2. If you can't rule out the possibility that you're dreaming that $P$, then you don't know that $P$.

3. So you don't know that $P$.

For almost all values for $P$, it doesn't seem possible to rule out the possibility that one is dreaming that $P$. If we accept premise 2 in the skeptical argument (for almost all values for $P)$, then we have to conclude that there is almost nothing that we know. That conclusion is startling, and seems to conflict with the fact that we are ordinarily happy to attribute all kinds of knowledge to people who haven't ruled out the possibility that they are dreaming.

Austin (1946) observes that we ordinarily attribute knowledge to someone just in case they are able to rule out reasonable alternatives to what she claims to know (where an alternative to a proposition $P$ is a proposition that implies the falsity of $P$ ). ${ }^{4}$ For example, to know that the bird in the garden is a goldfinch, one has to be able to rule out the alternative

\footnotetext{
${ }^{3}$ Grice's (1989) criticism of "A-philosophy" raises this worry about a variety of expressions, including "remember", "seeing... as", "voluntary" and "trying". Travis (1985) defends central elements of ordinary language philosophy against Grice's criticisms of "A-philosophy". For contemporary examples of Grice's criticism, see, e.g., Bach (2007), Kauppinen (2007, p. 104) and Soames (2003, Ch. 9). For a response to these contemporary versions of the worry, see Baz (2012b, Ch. 1).

${ }^{4}$ Lawlor (2013) develops an Austin-inspired "reasonable alternatives" theory of knowledge that is "a species of the genus relevant alternatives theory" (p. 74). For examples of relevant alternatives theories see Dretske (1970), Goldman (1976) and Stine (1976).
} 
that the bird in the garden is a woodpecker. One might be able to do that by observing that the bird in the garden has eye-markings characteristic of goldfinches (but not woodpeckers). In an ordinary birdwatching situation, no one would count the fact that the person who claims to know that there's a goldfinch in the garden hasn't ruled out the alternative that what she takes to be a bird is in fact a stuffed goldfinch (or the alternative that she is dreaming that there is a goldfinch in the garden) as disqualifying her as knowing that there's a goldfinch in the garden.

Do Austin's observations about how we ordinarily use "knows" pose a challenge to the skeptical argument? If we assume that ordinary use tells us directly what "knows" means, then premise 2 in the skeptical argument looks like it involves a distortion of the meaning of "knows" - premise 2 sets far higher standards for knowledge ascriptions than we ordinarily require. And if the skeptical argument involves a distortion of the meaning of "knows", then it doesn't really have the startling conclusion that it initially seemed to have-that we can't know many of the ordinary things we take ourselves and others to know.

But there is an influential argument that there is no direct inference from how an expression is ordinarily used to what that expression means, because "there are two apparently distinct questions that can be asked about what someone says. We can ask whether it is true, or we can ask whether it was appropriately or reasonably said" (Stroud, 1984, p. 57). There needs to be some additional reason to think that facts about ordinary use should be explained by facts about the meaning of an expression rather than facts of some other type, such as facts about when the expression can be appropriately asserted (Searle 1969, $§ 6.3$; Stroud 1984, pp. 62-63). Unless some such reason is forthcoming, then it doesn't follow that the second premise in the skeptical argument involves a distortion of the meaning of "know". 5

\footnotetext{
${ }^{5}$ Stroud (1984, p. 75 n. 17) says that his argument is indebted to Grice. Kaplan (2000) criticizes Stroud's separation of truth and acceptability.
} 
The constructive project in contemporary ordinary language philosophy takes on this challenge by first agreeing that there is no direct relation between the ordinary use of an expression and the meaning of that expression but then attempting to give additional reasons in favor of thinking that facts about the ordinary use of an expression provide evidence of the meaning of that expression. Premise 2 in the semantic stage of the constructive project marks this important difference between classic and contemporary forms of ordinary language philosophy: it is now widely recognized that any inference from how an expression is ordinarily used to the meaning of that expression will have to be an inference to the best explanation.

For example, DeRose (2005, 2009, Ch. 2) argues for contextualism about knowledge ascriptions - the view that the semantic content of "S knows that p" can vary in different contexts - on the grounds that it best explains truth-value and acceptability judgments about the ordinary use of knowledge ascriptions. ${ }^{6}$ DeRose is aware that he needs to respond to a challenge of this type in order to support his claim that it is a semantic feature about "S knows that p"-namely, that it can vary its (semantic) content in different contextsthat best explains the data from ordinary use. The "warranted assertibility objection" to semantic versions of epistemic contextualism claims that the patterns in ordinary use that the contextualist takes to support a semantic conclusion—namely, that what is said by uses of "S knows that p" is judged true and appropriate in certain ("low standard") contexts, and what is said by "S doesn't know that p" is judged true and appropriate in certain ("high standard") contexts — can best be explained in terms of non-semantic facts about when it is conversationally appropriate to say "S knows/doesn't know p". There is a lively debate concerning whether contextualists can convincingly respond to the warranted assertibility

\footnotetext{
${ }^{6}$ DeRose (2009, p. 47) writes: "The best grounds for accepting contextualism come from how knowledgeattributing (and knowledge-denying) sentences are used in ordinary, non-philosophical talk: What ordinary speakers will count as 'knowledge' in some non-philosophical contexts they will deny is such in others". See Hansen (2012) for criticism of the experimental method DeRose uses to gather his ordinary language data. Baz (2012b) argues that the contexts that contextualists employ in their experiments are not ordinary contexts, and so do not provide genuine evidence of ordinary use.
} 
objection and other types of pragmatic explanations of the data from ordinary use (see, e.g., Brown 2006, Davis 2007, DeRose 2009, Ch. 3, Rysiew 2001, and Stainton 2010 for discussion and debate).

There are significant disagreements about what features the meaning of expressions need to have in order to explain patterns of ordinary use, even among contemporary philosophers who say they are doing ordinary language philosophy (DeRose 2009, p. 51 and Travis 1989, p. 155, for example). DeRose's epistemological contextualism is compatible with standard (Kaplanian) semantic theories of how meaning and context interact. ${ }^{7}$ Standard theories treat the meaning of linguistic expressions as a function from contextual parameters (like time, location, speaker, etc.) to contents (extensions). That captures the way in which expressions like "I" and "now" have a linguistic meaning that remains fixed, while the things those expressions are used to refer to systematically vary depending on particular features of the context (who the speaker is for "I" and what the time is for "now", e.g.). DeRose's contextualism is a modest extension of the standard theory from obviously context sensitive expressions like "I" and "now" to the expression "knows", according to which the word "knows" can vary its content depending on what the relevant epistemic standards are.

While DeRose pursues a version of the constructive project in contemporary ordinary language philosophy within the framework of standard semantic theory, Travis $(1978,1981$, $1989,2008)$ rejects the idea that ordinary use can be explained in terms of systematic relations between the meaning of linguistic expressions and particular contextual parameters. According to Travis's "occasion-sensitive" view, once one appreciates the variety of things an expression can be used to say, the task of identifying an informative and non-ad-hoc set of contextual parameters on which the content of an expression depends looks hopeless. What a sentence is used to say or what an expression is used to refer to on a particular

\footnotetext{
${ }^{7}$ See DeRose (2009, p. 3) and Kaplan (1989).
} 
occasion is fixed by a "correct understanding" of the use of that expression on an occasion, and a correct understanding of the use of an expression on an occasion is how a "reasonable judge" would understand it. Reasonableness, and hence also correct understanding, is not equivalent to an appreciation of some specific set of contextual parameters. So the linguistic meaning of an expression should not be understood - as it is on the standard theory of how meaning and context interact-as a function from some specific set of contextual parameters to an extension. Travis's version of the constructive project might therefore be regarded as a closer continuation of the spirit of classic ordinary language philosophy than DeRose's in the respect that it aligns with the classic idea that the resources of systematic semantic theory are ill-suited for explaining ordinary use because "ordinary language has no exact logic" (Strawson, 1950, p. 344). ${ }^{8}$

While there are deep disagreements about how best to explain the way expressions are ordinarily used, contemporary ordinary language philosophers are not prone to make the direct inference from the ordinary use of an expression to the meaning of that expression that classic ordinary language philosophers have been criticized for.

\subsection{How are Expressions Ordinarily Used?}

In his criticism of the direct move from the ordinary use of "knows" to the meaning of "knows", Stroud grants the data that Austin cites about ordinary use. But another objection to classic ordinary language philosophy disputes Premise 1 in the constructive project, by challenging the legitimacy of the data the project is based on. Mates (1964) (originally published in 1958) argues that ordinary language philosophers employ unreliable methods when collecting data about how we ordinarily use expressions, and he cites the fact that there isn't agreement about how the word "voluntary" is ordinarily used even among advocates of ordinary language philosophy as evidence that the facts about ordinary use are

\footnotetext{
${ }^{8}$ Thanks to an anonymous reviewer for emphasizing how Travis is more closely related to classic ordinary language philosophy than other contemporary philosophers who are engaged in the constructive project.
} 
murkier than classic ordinary language philosophers assume.

Buckwalter (2010) and Feltz and Zarpentine (2010) are contemporary examples of a Mates-style challenge to the contextualist's constructive ordinary language project in epistemology. ${ }^{9}$ Mates, Buckwalter, and Feltz and Zarpentine all argue that existing armchair methods of gathering data about the ordinary use of knowledge ascriptions are inadequate, but their contemporary versions of Mates's challenge involve experiments that fail to confirm the claims that contextualists and "anti-intellectualists" make about the ordinary use of knowledge ascriptions. The experimental challenge to armchair methods of collecting data about ordinary use is part of a much larger trend of skepticism about armchair methods of collecting data in both linguistics and philosophy.

But in a more recent experimental investigation of the armchair judgments made by contextualists, Hansen and Chemla (2013b) confirm contextualists' judgments about "know", color terms, and other expressions. This finding comports with recent experimental investigations in linguistics showing that experts' armchair judgments about the acceptability of variety of examples align with the judgments of ordinary speakers in experimentally controlled circumstances (Sprouse et al., 2013), and that there is consistency between the judgments of expert linguists and non-specialists who have some familiarity with cognitive science (Culbertson and Gross, 2009). ${ }^{10}$ The recent experimental turn in how philosophers collect and analyze linguistic data has therefore provided both a means of renewing Mates's challenge and the tools for defenders of ordinary language philosophy to answer it.

\footnotetext{
${ }^{9}$ As DeRose (2011, p. 91) points out, though Feltz and Zarpentine don't take themselves to be presenting a challenge to contextualism, but to "anti-intellectualism" (a form of invariantism about "knows"), their study nevertheless still seems to pose a challenge to contextualism.

${ }^{10}$ For discussion of these and related studies, and an overview of empirical and conceptual issues bearing on the role of intuitions as evidence for linguistic theory, see Maynes and Gross (2013).
} 


\subsubsection{An alternative conception of statements about "ordinary use"}

These contemporary debates about the reliability of ordinary language philosophers's methods of collecting evidence of how expressions are used assume, with Mates, that the standards for evaluating statements about ordinary use are those appropriate for evaluating descriptive statements, and with Fodor and Katz (1963, p. 71) that claims about ordinary use "should be subject to the same modes of confirmation and disconfirmation that linguists accept".

Cavell (1964) (originally published in 1958) rejects the assumption that the statements of ordinary language philosophers are subject to the same standards as the statements of empirical linguists. Cavell claims that statements about ordinary use made by ordinary language philosophers are "categorial declaratives", which are like descriptions of the rules of games that "tell us how an action is done, or how it is to be done" (p. 94). For example, Cavell says that a statement like "'I know it' is not (ordinarily) said unless the speaker has great confidence in it" (p. 87) sometimes "sounds less like a descriptive statement than a rule". Cavell thinks that the "categorial", rule-giving, function of such statements about ordinary use has been overlooked. ${ }^{11}$

As Bates and Cohen (1972) observe in relation to Cavell's views about ordinary language, "explicating Cavell is no picnic", but recent work on what has been called "conceptual ethics" provides an alternative way of seeing how statements about ordinary language might differ from the claims made in empirical linguistics. Conceptual ethics concerns the general question "how should we use our words?", which can arise in many different particular forms, including "resolving ambiguity, precisifying a vague term, setting a contextual parameter, or in any other way determining how some antecedently indeterminate

\footnotetext{
${ }^{11}$ For attempts to explicate Cavell's approach to ordinary language philosophy, see Gustafsson (2005) and Hammer (2002, Ch. 1). Jackman (2001) critiques "conventionalist" attempts (Searle, 1969; Vendler, 1967) to explain how statements about ordinary language are different from the claims made by an empirical linguist. Sandis (2010) argues that ordinary language philosophy is interested in "objective facts about linguistic norms" and not in the regularities of use that experimental philosophers and linguists uncover.
} 
matter of meaning should be settled" (Plunkett and Sundell, 2013, p. 3). ${ }^{12}$

If the statements made by ordinary language philosophers are understood not as attempts to give an empirically adequate description of some antecedently settled meaning of an expression, but as attempts to fix or push a particular precisification or expansion of a meaning for some purpose, then the standard charge that their methods of empirical verification are not up to professional standards in linguistics are missing the point. For example, it might be worthwhile to see Austin's (1966) discussion of subtle distinctions between the meaning of "intentionally" and "deliberately" not as a recording of pre-existing distinctions between the ordinary use of those expressions, but as an attempt to fix those expressions to subtly different concepts with the aim of providing us with more precise linguistic tools to work with in discussions of action and responsibility. ${ }^{13}$ This way of thinking of ordinary language philosophy, however, involves a substantial departure from the constructive project because its aim is not to discover distinctions that are present in ordinary use, but to revise ordinary use for certain purposes. ${ }^{14}$

\subsection{The Metaphysical Stage of the Constructive Project}

Most of the argumentative weight in contemporary ordinary language philosophy is focused on the semantic stage in the constructive argument. It is difficult enough to make a convincing case that the meaning of a particular expression has some particular semantic feature(s) F, and the further step of drawing conclusions about the nature of some aspect of

\footnotetext{
${ }^{12}$ Chalmers (2012, pp. 10-11) points out the relevance of "what expressions ought to mean" for contemporary ordinary language philosophy. For an outline of conceptual ethics, see Burgess and Plunkett (2013a,b).

${ }^{13}$ Interpreting Austin as aiming at giving empirically adequate descriptions of how expressions are actually used runs into the difficulty that he would be mistaken about some of his central cases, including ordinary judgments about "intentionally" and "deliberately". See Hansen and Chemla (2013a) for experimental evidence to that effect.

${ }^{14}$ Jackman (2001, p. 322) raises a similar worry about attempts to understand ordinary language philosophers as proposing how we should use our words. And see Wilson (2006) for a view that shares some sympathies with the objectives of ordinary language philosophy (see pp. 18-19, e.g.) but which holds that our "linguistic training" in ordinary use "has not prepared us adequately for dealing with a vexatious world" (p. 19) and can lead us astray in various circumstances.
} 
non-linguistic reality on the basis of that meaning adds another level of complexity to the constructive argument. Some theorists explicitly refrain from drawing any metaphysical conclusions from the semantic facts. Bach (1986, p. 573) says, for example, that in doing semantics for natural languages one is engaged in "natural language metaphysics", which involves trying to answer the question "what do people talk as if there is?", but which does not try to answer the traditional metaphysical question: "What is there?"15

But some contemporary philosophers maintain that the semantic facts about "knows" (e.g.) should constrain accounts of the non-semantic facts (about knowledge, e.g.). For example, Ludlow (2005, p. 13) says

any investigation into the nature of knowledge which did not conform to some significant degree with the semantics of the term "knows" would simply be missing the point... epistemological theories might be rejected if they are in serious conflict with the lexical semantics of "knows".

Why should the semantics of "know" constrain the metaphysics of knowledge? If we assume that the semantics of an expression like "knows" captures the ordinary understanding of knowledge, then the following argument gives one motivation for wanting such a constraint: ${ }^{16}$

1. If we want our philosophical theories (of knowledge, e.g.) to address the concerns that led us to philosophical investigation in the first place, then they need to be about the relevant objects of investigation as they are "ordinarily understood outside of strictly philosophical discourse". (Alexander and Weinberg, 2007, p. 58)

2. We do want our philosophical theories (of knowledge, e.g.) to address the concerns that led us to philosophical investigation in the first place.

\footnotetext{
${ }^{15}$ Pelletier (2011) argues that nothing about the nature of "reality" follows from the semantics of mass and count terms.

${ }^{16}$ The semantics of "knows" might not capture the ordinary understanding of knowledge, if, e.g., there are good reasons to embrace a "minimalist" account of semantic content. See Borg (2004, 2012).
} 
3. So our philosophical theories need to be about the relevant objects of investigation (knowledge, e.g.) as they are ordinarily understood outside of strictly philosophical discourse. $^{17}$

Whatever appeal the preceding argument has does not extend to scientific or technical matters like tautology or connectionist theories of mind, because there is no reason to think that ordinary understanding should impose any constraints on how those matters are understood (Knobe and Nichols, 2008, p. 8; Alexander and Weinberg, 2007, n. 7). It is limited to those topics that ordinary speakers regularly deal with, like whether someone knows something, or whether someone is responsible for doing something or not.

One worry about the argument is that it doesn't allow for the possibility that the concern that leads us to philosophical investigation is to understand the topic, whatever it turns out to be. It may turn out that in the course of philosophical theorizing about knowledge (e.g.) that we discover good reasons to refine our ordinary understanding of the topic. For example, Hazlett (2010, p. 500) has argued that there is reason to think that the "best candidate to serve as the meaning of 'knows' in ordinary talk' is non-factive (in order to explain the acceptability of sentences like "Everything he knows is wrong"), while the type of knowledge that is of genuine interest in epistemology is factive. ${ }^{18}$

One might instead argue that semantics constrains metaphysics if one accepts that se-

\footnotetext{
${ }^{17}$ See Knobe and Nichols (2008, pp. 8-9) for a related argument. Hanfling (2000, p. 235) argues that the ordinary meaning of "meaning" should constrain permissible theories of what meaning is (the argument is directed against Putnam's externalist theory of natural kind terms).

${ }^{18}$ See Stokke (2013) for criticism of Hazlett's argument that "knows" in ordinary language is non-factive. Abbott (2013) argues that evidence from cognitive psychology about functional differences between declarative and procedural memory threatens Stanley's (2011) argument that the semantics of "knows how to" provides convincing evidence in support of an "intellectualist" theory of knowledge-how. Also relevant here is Carnap's $(1956, \S 2$ ) conception of "explication", which involves "making more exact a vague or not quite exact concept used in everyday life... or rather of replacing it by a newly constructed, more exact concept". Carnap gives as examples of fruitful explications Frege and Russell's replacement of the "not quite exact meaning" that the term "two" has in everyday life with the concept of the class of pair-classes and the replacement of the "concept of truth as used in everyday language" with the semantical concept of truth (p. 8). It might turn out, in other words, that in the course of philosophical theorizing we discover that the meanings of the ordinary expressions that we began the investigation with can't do the precise work we need them to do and we have to create more refined semantic tools.
} 
mantic theories are in the business of stating truth conditions for declarative sentences of natural languages (Chalmers 2012, pp. 4-5 calls this the "disquotational argument"). ${ }^{19}$ Such a semantics would generate truth conditions like the following:

"S knows that $\mathrm{P}$ " is true iff $\mathrm{S}$ has ruled out all of the reasonable alternatives to $\mathrm{P}$.

But given that truth is disquotational (i.e., "S knows that $\mathrm{P}$ " is true iff $\mathrm{S}$ knows that $\mathrm{P}$ ), the truth condition for "S knows that P" would entail the following:

$\mathrm{S}$ knows that $\mathrm{P}$ iff $\mathrm{S}$ has ruled out all of the reasonable alternatives to $\mathrm{P}$.

Which is a claim about the conditions under which $\mathrm{S}$ knows that $\mathrm{P}$ (i.e. a claim about the metaphysics of knowledge). So if semantics involves stating truth-conditions, then given the disquotational nature of truth, it entails metaphysical commitments. ${ }^{20}$

The tight connection that exists between truth conditional semantics and metaphysics means that if there are reasons to reject a particular metaphysical theory of, e.g., knowledge, then those are also reasons to reject the corresponding semantics of "knows". If on the correct theory of knowledge we turn out not to know many of the things we ordinarily take ourselves to know, then the meaning of "knows" will be different from what we ordinarily take it to be, for example. That is, metaphysics constrains semantics just as much as semantics constrains metaphysics. As Ludlow (2005, p. 13) puts the idea:

Our task as investigators then is to solve a kind of complex equation in which we have partial information from linguistic theory, partial knowledge from our reflective analysis of knowledge, and we must find a way to balance the equation.

\footnotetext{
${ }^{19}$ See Gross (2006) for a much more in-depth exploration of this issue than is possible here.

${ }^{20}$ Thanks to Aidan Gray for this way of putting the argument. An anonymous referee points out that disquotationality only holds when there are no context sensitive expressions on the left hand side of the biconditional. Given that epistemic contextualists are committed to the context sensitivity of "knows", the disquotational argument won't be usable by contextualists.
} 
Thinking of semantics and metaphysics as interdependent is compatible with Austin's (1956) conception of ordinary language as the "first word" in philosophical investigations: because it evolves under the pressures of practical projects and interests, there is reason to look to ordinary language as a repository of distinctions that are richer than those that philosophers will be able to "think up in an armchair of an afternoon". On this understanding, we can depart from or revise ordinary language "if our interests are more extensive or more intellectual than the ordinary". But consulting ordinary language, in certain areas where ordinary language is rich with distinctions (one of Austin's examples of such an area was excuses), is a way of avoiding oversimplification and a technique for discovering aspects of reality that may otherwise go unnoticed.

\section{The critical project}

Classical ordinary language philosophy is standardly understood as accusing its philosophical opponents of not merely offering theories that are false, or of making arguments that are unsound, but of saying things that are nonsensical or meaningless because they stray from the ordinary use of the expressions involved. ${ }^{21}$ Malcolm (1951, p. 337) says that the "natural usage" of the sentence "I am here" is to reply to the question "Where are you?". A philosopher who wants to cite "I am here" as an example of a piece of "absolutely certain knowledge" (or a sentence that is true in virtue of the logic of demonstratives, as in Kaplan (1979, p. 82)), however, has "fallen into nonsense", because she is attempting to use the sentence in a way that has "broken away" from the ordinary use that is made of the sentence.

This kind of argument is subject to two of the objections discussed in relation to the constructive project: First, it relies on questionable data about the way that "I am here" is

\footnotetext{
${ }^{21}$ Sensitive exegetical work on classical proponents of ordinary language philosophy challenges this standard understanding. See, for example, Conant (1998) and Cavell (1979, p. 192). Thanks to Martin Gustafsson for emphasizing this point.
} 
ordinarily used. Certainly "I am here" is used in the way Malcolm describes, but is that its only use ${ }^{22}$ Second, it is subject to the worry that classic ordinary language philosophers move too quickly from observations about ordinary use to conclusions about the meaning of linguistic expressions. ${ }^{23}$

Is there any hope for a contemporary version of the critical project? Baz $(2012 b, a)$ makes the case that there is. Focusing on the expression "know that" (and cognates), Baz argues that questions posed by philosophers about the meaning of particular expressions (which Baz calls instances of "the theorist's question") are "fundamentally different from any question to which we might need to consider as part of our everyday employment of these expressions" (p. 91). Ultimately he aims to establish that not only is the theorist's question fundamentally different from everyday questions, but also to raise the possibility that, insofar as it lacks a connection to any of the ordinary purposes that one might have in asking whether someone knows something, we may be "tempted to think we understand" the theorist's question when we in fact do not (p. 123).

Baz's primary target is Williamson $(2004,2005,2007)$, who defends a type of armchair philosophical methodology against recent attacks from experimental philosophers. Williamson denies that what goes on when philosophers ask whether a concept applies to some imagined or real situation should involve eliciting intuitions as to whether or not the concept applies, where those intuitions are evidence that the concept applies or does not. That kind of approach both invites unnecessary investigations into whether or not philosophers' intuitions are widely shared and into how we could know that they are reliable indications of the subject matter under investigation, and it unnecessarily psychologizes the evidence available to philosophers. Instead, Williamson holds that when philosophers

\footnotetext{
${ }^{22}$ Malcolm allows that "there are other related usages", but does not discuss them.

${ }^{23}$ In the midst of making the argument that "I am here", used by the philosopher as an example of a piece of absolutely certain knowledge, is nonsense, Malcolm says "The sentence 'I am here' came to be used because its utterance served a certain purpose-namely, to inform someone of our whereabouts. Its meaning lies in this usage" (p. 337).
} 
ask whether a concept or expression applies to some imagined or real situation they are exercising our everyday capacity to apply concepts to actual and counterfactual situations (Williamson 2005 p. 12, 2007 p. 188). Insofar as that everyday capacity is reliable, the application of concepts to or use of expressions to describe imagined or real cases in philosophy should be reliable as well.

If Baz is right that the theorist's question is fundamentally different from everyday questions, then Williamson's defense of his armchair methodology, which ties the reliability of our answers to the theorist's question to the reliability of our everyday capacity to apply concepts to encountered situations, fails. ${ }^{24}$ Baz aims to establish the existence of a fundamental difference between "the theorist's question" about knowledge and ordinary questions about knowledge by arguing for the following two claims:

1. The capacity to understand and competently answer everyday questions is essentially the capacity to see and properly respond to what may be called 'their point' - the particular human interest of which they are expressive.

2. 'The [philosopher's] question has no point, in the relevant sense; it invites us to apply our words to some given case apart from any non-purely-theoretical interest that anyone might have in that case' (p. 105)

Baz's approach to supporting (1) and (2) is to work through an extensive list of examples of what we are doing 'outside philosophy' when we judge whether or not someone knows something, and he makes the case that in 'everyday' (non-philosophical) conversation, we never care about anything even resembling the bare (theorist's) question that arises in philosophical thought experiments. ${ }^{25}$ When we ordinarily want to know if someone knows, it's always in the service of some other purpose: I may ask you if you know in

\footnotetext{
${ }^{24}$ The remainder of this section contains material from Hansen (2013).

${ }^{25}$ Compare Kaplan (1991), who argues against "a pure theory of justification... cleansed of the concerns proper to the realm of the ordinary" (p. 154).
} 
order to see if you have some particular piece of information, or if you're in a position to offer an assurance that something is the case, etc. But none of those questions, Baz argues, come to the same thing as the theorist's question. He concludes that the philosopher's question about knowledge is fundamentally different from everyday questions about knowledge because it is detached from whatever point there may be in asking whether someone knows something in everyday conversation.

There are various ways that Baz's argument can be resisted. One could argue that understanding and answering everyday questions does not always require seeing what the point of asking them is. Or one could object that Baz's survey of ordinary use isn't extensive enough, and there is in fact some situation that could arise in a non-philosophical conversation that is analogous to the theoretical question about knowledge that arises in philosophical thought experiments. Both of those responses involve denying that there is a fundamental difference between ordinary questions about knowledge and the theorist's question. Or one might grant that there is a fundamental difference between the way that a word like 'know' is ordinarily used and the way that philosophers use it, but reject the idea that this is a problem for philosophy. Some might even say that this is why we shouldn't ask ordinary, non-expert speakers for their judgments about philosophical cases.

Even if one does not accept Baz's radical conclusion that the theorist's question has no point (in the sense of not being connected with any ordinary human interest), his argument cannot be ignored by those contemporary philosophers who invoke the responses of "ordinary" speakers (e.g., contextualists, experimental philosophers), because there are independent reasons to doubt that ordinary speakers reliably understand the questions they are asked in experimental situations in the way philosophers do.

Baz's critical project aligns with work in experimental psychology showing that different senses of why a question is being asked can influence what is considered an appropriate response. From the experimenter's perspective, the point of asking certain questions may 
be obvious, but from the perspective of the participant it is easy to misunderstand what the experimenter is asking. For example, Mercier (2011) argues that findings of apparent intercultural variation in reasoning can be explained in terms of variation in how culturally relevant the questions are to the participants. Participants' understanding of experimental settings can also systematically vary from that expected by the experimenter, which may alter the interpretation of their responses (Hilton, 1995; Politzer, 2004; Schwarz, 1996). ${ }^{26}$

If the point of asking whether someone knows something in ordinary conversation differs systematically from the point of asking whether someone knows in the context of a formal experiment or a philosophical thought experiment, that poses a problem for the use of what ordinary speakers would say in support of - or as a way of challengingphilosophical theories, because ordinary speakers may simply not understand the examples in the way philosophers intend them to.

\section{Conclusion}

Reports of the death of ordinary language philosophy are greatly exaggerated. Philosophers are engaged in intense debates about the three central elements of the constructive project in contemporary ordinary language philosophy:

- what the data about the ordinary use of philosophically significant expressions like "knows" are, and what the best methods for collecting such data are;

- what the best ways are to explain data about the way philosophically significant expressions like "knows" are ordinarily used;

- and what metaphysical significance (if any) the linguistic meaning of expressions like "knows" has.

\footnotetext{
${ }^{26}$ See Cullen (2010) for an application of these worries to some work conducted by experimental philosophers.
} 
The critical project has received less attention from contemporary philosophers, but if the argument is convincing it poses an important challenge to standard methods of data collection that rely on the judgments of ordinary speakers (that includes, ironically, the constructive project in contemporary ordinary language philosophy). Both those philosophers who aim to challenge claims about the way expressions are ordinarily used (experimental versions of Mates's challenge discussed above, e.g.) and those who aim to support claims about the way expressions are ordinarily used (by uncovering evidence that the judgments of ordinary speakers in experimental tasks align with the judgments of philosophers, e.g.) shouldn't ignore Baz's challenge: it is possible that by removing expressions from the situations in which they are ordinarily used and asking for responses to those expressions in situations that have been systematically stripped of their connection to practical interests and projects, philosophers are creating experimental artifacts rather than gathering data that bears on the meaning of those expressions. ${ }^{27}$

Warnock (1998) writes that “the label 'ordinary language philosophy' was more often used by the enemies than by the alleged practitioners of what it was intended to designate". But that is changing. A growing group of contemporary philosophers is willing to appropriate not just the methods of ordinary language philosophy, but the label as well, and the debates those philosophers participate in are flourishing.

\section{References}

Abbott, Barbara (2013). "Linguistic Solutions to Philosophical Problems: The Case of Knowing How". Philosophical Perspectives 27, 1-21.

Alexander, Joshua and J. Weinberg (2007). "Analytic Epistemology and Experimental Philosophy". Philosophy Compass 2(1), 56-80.

\footnotetext{
${ }^{27}$ I think that with a certain amount of experimental ingenuity philosophers can respond to Baz's challenge by designing experiments that retain connections with practical interests and projects. For a brief discussion of this possibility, see Hansen (2013).
} 
Austin, J.L. (1946). “Other Minds”. Aristotelian Society Supplementary Volume 20, 148187.

Austin, J.L. (1956-1957). "A Plea for Excuses". Proceedings of the Aristotelian Society 57, $1-30$.

Austin, J.L. (1962). Sense and Sensibilia. Oxford: Oxford University Press.

Austin, J.L. (1966). “Three Ways of Spilling Ink". The Philosophical Review 75(4), 427440.

Bach, Emmon (1986). "Natural Language Metaphysics". In R. B. Marcus, G. Dorn, and P. Weingartner (Eds.), Logic, Methodology and Philosophy of Science, Volume VII, Amsterdam, pp. 573-595. North Holland.

Bach, Kent (2007). "Regressions in Pragmatics (and Semantics)". In N. Burton-Roberts (Ed.), Pragmatics, Palgrave Advances in Linguistics. Basingstoke: Palgrave MacMillan.

Bates, Stanley and T. Cohen (1972). "More on What We Say”. Metaphilosophy 3(1), 1-24.

Baz, Avner (2012a). "Must Philosophers Rely on Intuitions?". Journal of Philosophy 109(4), 316-337.

Baz, Avner (2012b). When Words Are Called For: A Defense of Ordinary Language Philosophy. Cambridge, Massachusetts: Harvard University Press.

Borg, Emma (2004). Minimal Semantics. Oxford: Clarendon Press.

Borg, Emma (2012). Pursuing Meaning. Oxford: Oxford University Press.

Brown, Jessica (2006). "Contextualism and Warranted Assertibility Maneuvers". Philosophical Studies 130(3), 407-435.

Buckwalter, Wesley (2010). “Knowledge Isn't Closed on Saturdays: A Study in Ordinary Language". Review of Philosophy and Psychology 1(3), 395-406.

Burgess, Alexis and D. Plunkett (2013a). "Conceptual Ethics I". Philosophy Compass 8(12), 1091-1101.

Burgess, Alexis and D. Plunkett (2013b). "Conceptual Ethics II". Philosophy Compass 8(12), 1102-1110.

Carnap, Rudolf (1956). Meaning and Necessity (2nd ed.). Chicago: University of Chicago Press.

Cavell, Stanley (1964). "Must We Mean What We Say?". In V. Chappell (Ed.), Ordinary Language, pp. 75-112. Englewood Cliffs, New Jersey: Prentice-Hall. 
Cavell, Stanley (1979). The Claim of Reason: Wittgenstein, Skepticism, Morality and Tragedy. Oxford: Oxford University Press.

Chalmers, David (2012). "Eighteenth Excursus: Conceptual Analysis and Ordinary Language Philosophy". In Constructing the World (Extended ed.). http://consc.net/books/ctw/extended.html.

Chapman, Siobhan (2005). Paul Grice, Philosopher and Linguist. Houndmills, Basingstoke: Palgrave MacMillan.

Conant, James (1998). "Wittgenstein on Meaning and Use". Philosophical Investigations 21(3), 222-250.

Culbertson, Jennifer and S. Gross (2009). “Are Linguists Better Subjects?”. British Journal of Philosophy of Science 60(4), 721-736.

Cullen, Simon (2010). "Survey-Driven Romanticism". Review of Philosophy and Psychology 1(2), 275-296.

Davis, Wayne A. (2007). "Knowledge Claims and Context: Loose Use". Philosophical Studies 132(3), 395-438.

DeRose, Keith (2005). "The Ordinary Language Basis for Contextualism, and the New Invariantism”. The Philosophical Quarterly 55(219), 172-198.

DeRose, Keith (2009). The Case for Contextualism. Oxford: Oxford University Press.

DeRose, Keith (2011). “Contextualism, Contrastivism, and X-Phi Surveys”. Philosophical Studies 156(1), 81-110.

Dretske, Fred I. (1970). "Epistemic Operators”. The Journal of Philosophy 67(24), 10071023.

Feltz, Adam and C. Zarpentine (2010). "Do You Know More When It Matters Less?". Philosophical Psychology 23(5), 683-706.

Fodor, Jerry A. and J. J. Katz (1963). “The Availability of What We Say”. The Philosophical Review 72(1), 57-71.

Forguson, Lynd (2001). "Oxford and the 'Epidemic' of Ordinary Language Philosophy”. The Monist 84(3), 325-345.

Goldman, Alvin I. (1976). "Discrimination and Perceptual Knowledge". The Journal of Philosophy 73(20), 771-791.

Grice, H.P. (1961). "The Causal Theory of Perception". Proceedings of the Aristotelian Society 35, 121-168. 
Grice, H.P. (1989). "Logic and Conversation". In Studies in the Way of Words. Cambridge, Massachusetts: Harvard University Press.

Gross, Steven (2006). "Can Empirical Theories of Semantic Competence Really Help Limn the Structure of Reality?". Noûs 40(1), 43-81.

Gustafsson, Martin (2005). "Perfect Pitch and Austinian Examples: Cavell, McDowell, Wittgenstein, and the Philosophical Significance of Ordinary Language". Inquiry 48(4), 356-389.

Hammer, Espen (2002). Stanley Cavell: Skepticism, Subjectivity, and the Ordinary. Cambridge: Polity Press.

Hanfling, Oswald (2000). Philosophy and Ordinary Language: The Bent and Genius of our Tongue. London: Routledge.

Hansen, Nat (2012). "On an Alleged Truth/Falsity Asymmetry in Context Shifting Experiments". The Philosophical Quarterly 62(248), 530-545.

Hansen, Nat (2013). "Review of Avner Baz, When Words Are Called For: A Defense of Ordinary Language Philosophy". The Philosophical Quarterly 64(254), 179-181.

Hansen, Nat and E. Chemla (2013a). "Beating a Dead Donkey: Linguistic Experiments and Ordinary Language Philosophy". Unpublished ms. University of Reading and LSCP.

Hansen, Nat and E. Chemla (2013b). "Experimenting on Contextualism". Mind \& Language 28(3), 286-321.

Hazlett, Allan (2010). "The Myth of Factive Verbs". Philosophy and Phenomenological Research $\operatorname{LXXX(3),497-522.}$

Hilton, Denis J. (1995). “The Social Context of Reasoning: Conversational Inference and Rational Judgment”. Psychological Bulletin 118(2), 248-271.

Jackman, Henry (2001). "Ordinary Language, Conventionalism and a priori Knowledge". dialectica 55(4), 315-325.

Kaplan, David (1979). "On the Logic of Demonstratives". Journal of Philosophical Logic 8(1), 81-98.

Kaplan, David (1989). "Demonstratives: An Essay on the Semantics, Logic, Metaphysics and Epistemology of Demonstratives and Other Indexicals". In J. P. Joseph Almog and H. Wettstein (Eds.), Themes From Kaplan, pp. 481-563. Oxford: Oxford University Press.

Kaplan, Mark (1991). “Epistemology on Holiday”. Journal of Philosophy 88(3), 132-154. 
Kaplan, Mark (2000). “To What Must an Epistemology be True?”. Philosophy and Phenomenological Research 61(2), 279-304.

Kauppinen, Antti (2007). "The Rise and Fall of Experimental Philosophy". Philosophical Explorations 10(2), 95-118.

Knobe, Joshua and S. Nichols (2008). "An Experimental Philosophy Manifesto". In J. Knobe and S. Nichols (Eds.), Experimental Philosophy, pp. 3-16. Oxford: Oxford University Press.

Laugier, Sandra (2013). Why We Need Ordinary Language Philosophy. Chicago: University of Chicago Press.

Lawlor, Krista (2013). Assurance: An Austinian View of Knowledge and Knowledge Claims. Oxford: Oxford University Press.

Ludlow, Peter (2005). "Contextualism and the New Linguistic Turn in Epistemology". In G. Preyer and G. Peter (Eds.), Contextualism in Philosophy: Knowledge, Meaning and Truth, pp. 11-50. Oxford: Oxford University Press.

Malcolm, Norman (1951). "Philosophy for Philosophers". The Philosophical Review 60(3), 329-340.

Mates, Benson (1964). "On the Verification of Statements about Ordinary Language". In V. Chappell (Ed.), Ordinary Language, pp. 64-74. Englewood Cliffs, New Jersey: Prentice-Hall.

Maynes, Jeffrey and S. Gross (2013). "Linguistic Intuitions". Philosophy Compass 8(8), 714-730.

Mercier, Hugo (2011). "On the Universality of Argumentative Reasoning”. Journal of Cognition and Culture 11(1-2), 85-113.

Noë, Alva (2005). “Against Intellectualism”. Analysis 65(4), 278-290.

Parker-Ryan, Sally (2012). “Ordinary Language Philosophy”. In Internet Encyclopedia of Philosophy. http://www.iep.utm.edu/ord-lang/.

Pelletier, Francis Jeffry (2011). "Descriptive Metaphysics, Natural Language Metaphysics, Sapir-Whorf, and All That Stuff: Evidence from the Mass-Count Distinction". The Baltic International Yearbook of Cognition, Logic and Communication 6, 1-46.

Plunkett, David and T. Sundell (2013). "Disagreement and the Semantics of Normative and Evaluative Terms”. Philosophers' Imprint 13(23), 1-37.

Politzer, Guy (2004). "Reasoning, Judgement and Pragmatics". In I. A. Noveck and D. Sperber (Eds.), Experimental Pragmatics, pp. 94-115. Palgrave MacMillan. 
Rysiew, Patrick (2001). "The Context-Sensitivity of Knowledge Attributions”. Noûs 35(4), 477-514.

Sandis, Constantine (2010). "The Experimental Turn and Ordinary Language”. Essays in Philosophy 11(2), 181-196.

Schwarz, Norbert (1996). Cognition and Communication: Judgmental Biases, Research Methods, and the Logic of Conversation. Mahwah, NJ: Lawrence Erlbaum Associates.

Searle, John (1969). Speech Acts. Cambridge: Cambridge University Press.

Soames, Scott (2003). Philosophical Analysis in the Twentieth Century, Volume II. Princeton: Princeton University Press.

Sprouse, Jon, C. T. Schütze, and D. Almeida (2013). "A Comparison of Informal and Formal Acceptability Judgments Using a Random Sample from Linguistic Inquiry 20012010”. Lingua 134, 219-248.

Stainton, Robert J. (2010). "Contextualism in Epistemology and the Context-Sensitivity of 'Knows"'. In J. K. Campbell, M. O'Rourke, and H. S. Silverstein (Eds.), Knowledge and Skepticism, pp. 113-139. Cambridge, Massachusetts: MIT Press.

Stanley, Jason (2008). "Philosophy of Language". In D. Moran (Ed.), The Routledge Companion to Twentieth Century Philosophy. New York: Routledge.

Stanley, Jason (2011a). Know How. Oxford: Oxford University Press.

Stanley, Jason (2011b). "Knowing (how)”. Noûs 45(2), 207-238.

Stanley, Jason and T. Williamson (2001). "Knowing How". The Journal of Philosophy 97(8), 411-444.

Stine, G.C. (1976). "Skepticism, Relevant Alternatives, and Deductive Closure". Philosophical Studies 29(4), 249-261.

Stokke, Andreas (2013). "Protagonist Projection”. Mind \& Language 28(2), 204-232.

Strawson, P.F. (1950). “On Referring”. Mind 59(235), 320-344.

Stroud, Barry (1984). The Significance of Philosophical Skepticism. Oxford: Oxford University Press.

Travis, Charles (1978). “Meaning versus Truth”. Dialogue 17(3), 401-430.

Travis, Charles (1981). The True and the False: The Domain of the Pragmatic. Number II:2 in Pragmatics and Beyond. Amsterdam: John Benjamins B.V.

Travis, Charles (1985). "On What is Strictly Speaking True". Canadian Journal of Philosophy 15(2), 187-229. 
Travis, Charles (1989). The Uses of Sense: Wittgenstein's Philosophy of Language. Oxford: Oxford University Press.

Travis, Charles (2008). Occasion-Sensitivity: Selected Essays. Oxford: Oxford University Press.

Vendler, Zeno (1967). "Linguistics and the A Priori". In Linguistics in Philosophy, pp. 1-32. Ithaca, NY: Cornell University Press.

Warnock, Geoffrey (1998). “Ordinary Language Philosophy, School of”. In E. Craig (Ed.), Routledge Encyclopedia of Philosophy. London: Routledge.

Williamson, Timothy (2004). “Philosophical 'Intuitions' and Scepticism about Judgement". dialectica 58(1), 109-153.

Williamson, Timothy (2005). “Armchair Philosophy, Metaphysical Modality and Counterfactual Thinking". Proceedings of the Aristotelian Society 105(1), 1-23.

Williamson, Timothy (2007). The Philosophy of Philosophy. Oxford: Blackwell.

Wilson, Mark (2006). Wandering Significance. Oxford: Oxford University Press.

Wittgenstein, Ludwig (1969). On Certainty. New York: Harper and Row. 